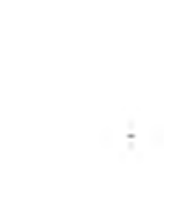

\title{
TAKE THE MOST OF THE STUDENTS' INPUT AND FEEDBACK TO PUSH A SUCCESSFUL LANGUAGE TEACHING
}

\section{Anton Suratno ${ }^{1}$}

Abstract: As we have recently obsenved that there has been a crucial change in most people's perception concerning approach to teaching. As Nunan has recently mentioned that in current language teaching development, there has been a clear and observable gradual move from a top-down to getting more and more bottom-up approach to the planning, implementation and evaluation of teaching and leaming program. (Nunan. 1996: 129). He is supported by Gandner and Miller with their interest in leamers' ausonomy (Gardner and Miller, 1996), also by Hutchison and Waters in their ESP leaming-centired approach (Huchison and Waters, 1993), There are some practical reasons why students' input and feedback are likely' to contribute to the success of the L-T programs.

This article aims to put forward an overview of the students 'potential contribution to the way to optimize the learning and teaching processes by way of considering the importance of their regular input and feedback that they give to help plan, monitor and review or evaluate the TL programs. In other words, this paper will try to see a differens perspective on achieving a good teaching program from the area beyond method of teaching.

Key words : Students input, students feedback, language teaching

\section{COMMON MISCONCEPTION CONCERNING WHAT MAKES}

\section{AN EFFECTIVE TEACHING}

When teachers are confronted with the question of what makes an effective teaching/learning, most of them think methods are the answer. Then,

1. Drs. Anton Suratno, MA. is a lecturer of the Faculty of Letters, Soegijapranata Catholic University, Semarang 
12 Celt, Volume I, Number I, December $2001: 11-18$

when they are asked further about the method which is likely to

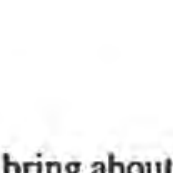
the most effective teaching outcomes they might hurriedly answer "communicative teaching method" simply because its popularity has long been believed as one of the most widely-accepted methods all over the world since the 1970's. The rest of them might answer differently by basing their arguments on every detail elements of methods such as what kind of approach the teacher has, or what kind of course design he is dealing with or which teaching procedure he is going through.

Debating on such topics might end up with an endless confusion and fnstration as everybody may claim that his opinion is the most correct one while in fact there is no superior or inferior method of teaching. (Scovel 1983, in Legutke, 1991). One has its own advantages and weaknesses and is specific in itself depending on the circumstances or teaching context the method is deployed."Each method is potentially to be a suitable and good method depending on these circumstances, i.e. whether the course is held in a formal or informal settings, whether it is for children or adults, whether it is for smaller group or larger one, whether it is targeted to EFL/ESL students or those who are learning their mother tongue."

Blum 1984, as quoted in Richards (1990) cited that "method is not the key variable to teaching success", in particular, in the era of leamercentredness (Tudor, 1996), which was initially developed by Nunan and other researchers in Australia (Nunan, 1996). Richards further stated that "Methods cannot ensure good learning, only good teachers can" (Richards, 1990), namely those who take the language learners "as the main reference point for decision-making with respect to both the content and the form of teaching". (Tudor, 1996). His opinion gets its ground in particular when we refer to the most secent principle stated by, teacher practitioners, DePorter et al., which is popularly called "Quantum Teaching", a belief about interaction (between people) which can turn an energy into light. Their main principle of making a good teaching is like this " Bring their (the students") world to us and let's take our (the teachers') world to them" A good teaching is a condition in which a teacher manages to fully understand the learners in order for them to understand the teachers. Thus, a successful teacher is the one who understands and believes that any potentials that the student possessed constitute a valuable asset which bring the success of the teaching. (DePorter, 1999). 
Blum as quoted by Richards (1990) further stated that a good Perpustakan Unika who is doing a good teaching is not characterized by any particular correct method but by:
A pre-planned curriculum
High expectations of students
Careful orientations of students to lessons
Clear and focused instruction
Close monitoring of progress
Re-teaching of points not understood
Class time used for learning

Smooth and efficient classroom routines

Instructional groups fit instructional needs

High standards of classroom behaviour

Positive personal interaction between teachers and students

Rewards and incentives for excellence.

(Bloom as quoted by Richards. 1990)

The question that we have to answer now is how all the above can be achieved through our practical day-to-day teaching practices, If the key word to achieving such an objective is taking the most of the students' involvement in the LT process which according to Tudor, is achievable through consultation and negotiation between teachers and students (Tudor, 1996), then we can argue that inviting as much students' regular input and feedback can provide first-hand information which, I believe, helps create a good quality teaching.

In the light of the above perspective, therefore, we should like to see three different components through the following section of the paper, i.e. first, some steps of instruction processes in which the students' feedback and input may be gathered: second, some demands or prerequisites to be met; and thirdly the result once the prerequisites are fulfilled.

\section{WHEN THE INPUT MAY BE GATHERED}

\section{Pre-teaching phase}

Students' input may be gathered prior to the teaching processes. Preteaching phase is one of the crucial phases during which some initial planning to instruction is taking place. It is the phase during which data are collected for the purpose of planning and developing materials. Needs analysis is one of the most typical ways of this initial input taking from the leamers, but for 
such a purpose, a teacher does not always need to deploy nt Perpustakan Unika is questionnaire unless a teacher is starting a totally new course, as it will be lengthy for analyzing the result.

To know students' strategies for learning, for instance, we can adopt this simple input questions like the following:

\begin{tabular}{|l|l|l|l|l|}
\hline No & \multicolumn{1}{|c|}{ Question types } & Often & $\begin{array}{l}\text { Some } \\
\text { times }\end{array}$ & Never \\
\hline 1 & Do you do extra tasks besides attending class? & & & \\
\hline 2 & Do you try to analyze grammatical system? & & & \\
\hline 3 & Doyou learn through watching TV or listening to a radio? & & & \\
\hline 4 & Do you switch to your mother longue when stuck? & & & \\
\hline 5 & Do you work in group? & & & \\
\hline 6 & Do you feel free to share ideas with your classmates? & & & \\
\hline 7 & Do you translate what you want to say or write? & & & \\
\hline 8 & Do you translate to understand reading or listening? & & & \\
\hline 9 & Do you repeat phrases or expression after the tape. TV? & & & \\
\hline 10 & Do you test your own progress? & & & \\
\hline 11 & Do you work cooperatively with friends? & & & \\
\hline 12 & Do you use imagery to help memorizing? & & & \\
\hline 13 & Can you read fast by scanning/skimming? & & & \\
\hline 14 & Can you summarize a passage? & & & \\
\hline 15 & Do you try to use new vocabulary? & & & \\
\hline 16 & Elc. & & & \\
\hline
\end{tabular}

Teachers may take advantage from taking this kind of data so that the teaching materials given can finally minimize the discrepancies or the gap between the students' expectations and classroom reality. By that way, the teaching is more likely to cater for a greater number of students with various learning styles, level of intelligence, learning pace, background knowledge, topic of interests, etc.

\section{During teaching phase}

In addition to doing some small quizzes to measure students' leaming progress, in this phase teachers can also do some informal feedback gathering whilst providing individual or small group counseling. Some questions like the following are usable to monitor the progress of the teaching, such as:

1 Can you really follow the lesson quite well?

Yes/No

2 Do you find any difficult areas to follow?

Yes/No

3 If yes, in which area do you find it difficult? Explain! 
A. Suratno, Take the Most of the Students' Input and Fee

4 Do you think the teaching progress match your learning pace?

5 What changes do you expect to have, please describe? Explain!

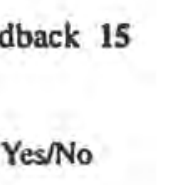

Through that way, teacher can, in fact, maintain a good communication with the students which in turn enhances their interrelationship and help create a democratic atmosphere. More importantly, once mismatch, shortcomings or deviation are identified, materials adjustment can be made much earlier so that a better quality teaching is more likely to take place and the whole progression of the teaching is closely identifiable and recordable.

\section{Post-teaching phase}

Input or feedback taken during the post-teaching phase constitutes a retrospection instrument. Teachers can make use of it as general evaluation over the whole process of instruction in order to know how successful it was and it provides a means of precisely planning the future teaching program.

1 Did you follow the lesson well?

2 Did you enjoy the classroom activities?

3 Did the teaching progress match your leaming pace?

4 Do you get what you expected before the class was begun?

5 What changes do you expect to have, please describe?

\section{THE PREREQUISITES WHICH SHOULD BE MADE AVAILABLE}

Expecting a situation or atmosphere in which students can remain playing their optimum roles in determining the success of teaching is not a simple and an instant process. The following prerequisites need to be consistently made available and considered.

\section{Persistent effort}

The process of the input taking should ideally be done consistently throughout the whole process of instruction, pre, during and post teaching. Each phase is interconnected one another, as each has a common goal i.e. achieving the success of the instruction. The process is clear through the following figure. 


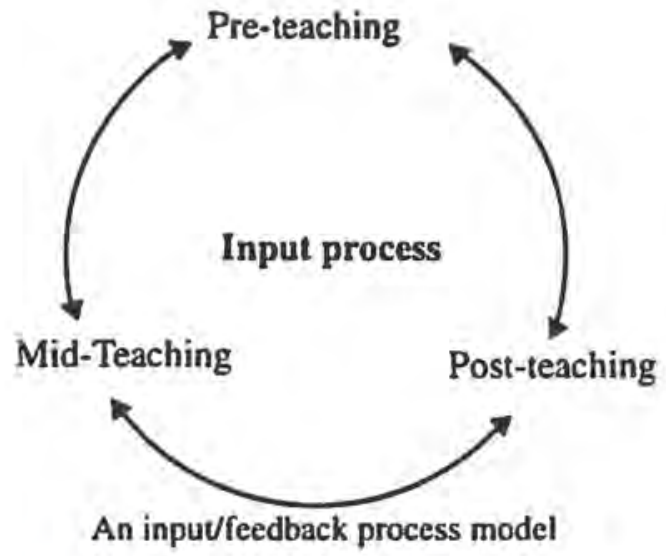

\section{Highlighting the students'role}

Wright said that "What individuals contribute to the group amounts to a set of expectations about how others will act and what roles they will adopt. (Wright, 1987). His opinion implies that the more the students are trusted to play more role, the more we can expect that they will contribute to the success of the instruction. Giving them more opportunities to provide input and feed-back can put them as the teachers' watchdog and whistleblower who can put the teachers back to their path when derailing.

\section{Democratic atmosphere}

A democratic communication is hardly achievable unless a warm and close interpersonal relationship between teachers and students is present. The old style of teacher-student relationship which tended to be like a superior and subordinate in our feudalistic and paternalistic culture has certainly to be gradually terminated as it is prone to produce repression rather than creativity in the part of the students. The research made by Goleman indicated that when the brain is working under intimidation and repression, the capacity of the nerves in the brain are diminishing and thus it tends to work improperly and think irrationally (Golemman as quoted by DePorter, 1999), hence, conducive atmosphere is a prerequisite to the students; active participation in the TL. 


\section{THE OUTCOMES THE TEACHERS CAN EXPECT}

Borrowing Tomlinson's terms (Tomlinson, 1998), the student's input gathering could be expected to:

1 help learners to feel at ease in learning

2 help learners develop confidence in learning

3 facilitate learners' self-investment

4 help acquire the points being taught

\section{Quoted from Tomlinson, 1998: 8-11}

Input gathering can also motivate students to leam as well as improve every individual student' responsibility to learning. The higher the students' level of motivation can be maintained, the greater the opportunity for success in language learning can be expected. Likewise, the more they take responsibility in learning, the higher their expectation for learning achievement.

As Legutke and Thomas (1991) suggest, implicit and explicit contribution donated by the students will be meaningful in an organized learning situation,

We refer here, to what the learners bring to the classroom, their prior knowledge, theirexperiences of the world in which they live, their experiences of and with the world of the target language and its culture, their social, cultural, and ethnic background and value systems; also their preferences with regard to other people, to themes, and ways of working; their knowledge of learning strategies and their expectations with regard to how learning should best be organized, their attitudes towards the subject of the school, to the teacher, their willingness to communicate, their readiness to take risks, their openness; and ability to emphatize..... (Legutke and Thomas, 1991)

\section{END WORDS}

All the above discussion is not particularly an elaboration of a research result as the argumentation is simply viewed and made in the light of the most current trend in the most up-to-date language teaching development where instruction is increasingly built up through a bottom-up processing rather than the other way around. In spite of some possible weaknesses, as it lacks scientific proofs, the writer's day-to-day experience in adopting input and feedback taking practices has indicated an almost consistent productive and effective result in lifting up the quality of TL. A decent and a well prepared research on the contribution of input and feedback to the success 
18 Celt, Volume 1, Number 1, December 2001 : $11-18$

of the TL should ideally be made in order to be more convinc Perpussakan Unika : truth of above argumentation.

\section{BIBLIOGRAPHY}

DePorter, Bobbi et al. (1999) Quantum Teaching: Mempraktikkan Quantum Teaching di Kelas-kelas. Boston: Kaifa.

Gardner, David and Miller, Lindsay (1997) A Study of Tertiary Level SelfAccess Facilities in Hong Kong. Hong Kong: David Gardner \&Lindsey Miller.

Hutchison, Tom and Waters, Allan (1993) English for Specific Purposes: A Learning Centred Approach. Cambridge: Cambridge University Press.

Legutke, Michael and Thomas, Howard (1991) Process and Experince in the Language Classroom. London: Longman Group UK Limited.

Nunan, David (1996) A Client-Centred Approach to Teacher development in Power Pedagogy \& Practice. Oxford: Oxford University Press.

Richards, J. (1990) The language Teaching Matrix. Cambridge: Cambridge University Press.

Tomlinson, Brian (1998) Material Development in Language Teaching. Cambridge: Cambridge University Press.

Tudor, Ian (1996) Learner-centredness as Language Education. Cambridge: Cambridge University Press.

Wright, Tony. (1987) Roles of Teachers and Learners. Oxford: Oxford University Press. 